\title{
Astragalus injection ameliorate Lipopolysaccaride- induced mice cognitive decline via relieving acute neuroinflammation and BBB damage as well as up- regulating BDNF-CREB pathway in chronic stage
}

\section{Huifeng Zhu}

Southwest University

Ke Liu

Southwest University

Ruhong Jiang

Chongqing Medical University

\section{Guoran Wan}

Chongqing Medical University

\section{Li Zou}

Southwest University

Xiaokang Zhu

Southwest University

Qiao Ren

Southwest University

Dong Wan

Chongqing Medical University

\section{Fang Cheng}

Henan University of Traditional Chinese Medicine

Shan Feng ( $\sim$ fengshan@swu.edu.cn )

Southwest University

\section{Research}

Keywords: Astragalus injection, Post-sepsis cognitive impairment, BBB, neuroinflammation, BDNF

Posted Date: January 1st, 2020

DOI: https://doi.org/10.21203/rs.2.19795/v1

License: (9) This work is licensed under a Creative Commons Attribution 4.0 International License. Read Full License 
Page $2 / 25$ 


\section{Abstract}

Background: Post-sepsis cognitive impairment is one of the major sequelae observed in survivors of sepsis. Although there are major concerns in the prevention, diagnosis and clinical management of sepsis, strategies for the prevention and treatment of related sequelae are still missing. Researches found that neuroinflammation, oxidative damage and vascular permeability are the main causes of brain damage during the systemic inflammation. Astragalus injection, with the function of regulating vascular endothelial function and immunity, is normally applied in viral myocarditis, viral enteritis, diabetic nephropathy and sepsis in clinical in China. However, it is unknown that whether it could ameliorate the post-sepsis cognitive impairment. Methods: In a LPS-induced mice model of sepsis, the protective effects of Astragalus injection on post-sepsis cognitive impairment was first evaluated. Then the influence of Astragalus injection on inflammatory cytokines secretion, BBB integrality and the expression of tight junction proteins in the acute sepsis stage were studied later. Followed by the neurodegeneration analysis and BDNF-CREB pathway evaluation in the chronic sepsis stage. What's more, in vitro experiment was further conducted to assess the effects of Astragalus injection on inflammatory cytokines secretion in microglia (BV2 cells). Results: Novel object recognition and Morris water maze tests show that Lipopolysaccharide (LPS)-induced sepsis in mice cause a long-term consequence of cognitive behavioral deficits, while Astragalus injection $(5 \mathrm{ml} / \mathrm{kg})$ could prevent the development of the above long-term cognitive decline. Mechanism studies show that Astragalus injection $(5 \mathrm{ml} / \mathrm{kg})$ not only could reverse LPS induced-neuroinflammation in mice and Bv2 cells, but also could protect the blood brain barrier dysfunction in acute stage. In addition, golgi staining and western blotting assays show that Astragalus injection could further prevent the neurodegeneration and up-regulate the BDNFCREB pathway during the chronic stage. Conclusions: Taken together, our data suggest that Astragalus injection could be a valuable therapy strategy for sepsis survivors in clinical, as it can produce protect effects on the post-sepsis cognitive impairment from many target spots and stages.

\section{Background}

Sepsis is a serious complication of infection in all countries which can lead to tissue damage, organ failure, and death. Although a precise estimate of the global epidemiological burden of sepsis is difficult to ascertain, some researches showed that it affects more than 30 million people worldwide every year, potentially leading to 6 million deaths [1]. However, sepsis does not end at hospital discharge. According to the Global Sepsis Alliance, many sepsis survivors suffer from the consequences of sepsis for the rest of their lives, such as sadness, difficulty sleeping, poor memory, difficulty concentrating, fatigue, anxiety (https://www.global-sepsis-alliance.org/sepsis). Although there are major concerns in the prevention, diagnosis and clinical management of sepsis, strategies for the prevention and treatment of related sequelae are still missing.

Post-sepsis cognitive impairment is one of the major sequelae observed in survivors of sepsis. Researches found that neuroinflammation, oxidative damage and vascular permeability are the main causes of brain damage during the systemic inflammation [2-6]. Cecal ligation and puncture (CLP) and 
lipopolysaccharide (LPS)-induced rodent model of sepsis are always applied to the research of septic encephalopathy. By using IL-1RI-/- mice, researchers demonstrated that the interleukin-1 (IL-1) mainly mediates the LPS-induced depressive effects and tumor necrosis factor-a (TNF-a) simply replaces IL-1 when the last cytokine is decient. Later, Imamura et al. further confirmed that IL-1 $\beta$ cause long-term potentiation deficiency in a CLP-induced mice sepsis model [7]. A similar study found that peripheral LPS challenge could promote microglial activation, which subsequently releasing pro-inflammatory cytokine and ultimately result in neuronal injury [8]. On the other side, the blood-brain barrier (BBB) is important for the maintenance of brain homeostasis. Peripheral production of proinflammatory cytokines and reactive oxygen species directly damage BBB, which in turn allow the transportation of cytoxic mediators into central nervous system, thus starting a vicious circle [9-11]. Taken together, keeping the integrality of BBB and inhibiting the neuroinflammation in brain are important in improving septic encephalopathy.

Astragali Radix is the dried roots of Astragalus membranaceus Bge. var. mongholicus (Bge.) Hsiao or A. membranaceus (Fisch.) Bge. It is collected in Chinese Pharmacopoeia (2015 edition), and is used to supplement qi, outthrust toxins, expel pus, close sores, and engender flesh according to the Chinese medicine theory. Astragalus injection, the extract from Astragali Radix by water extraction and alcohol precipitation method, is also included in Chinese Pharmacopoeia (2015 edition) and with stipulation that the astragaloside IV in this product should not be less than $0.08 \mathrm{mg} / \mathrm{ml}(1 \mathrm{ml}$ Astragalus injection equal to $2 \mathrm{~g}$ dried Astragali Radix crude drugs). Additionally, Astragalus injection with polysaccharoses, flavonoid, isoflavones, and saponin glycosides as main active constituents, is normally applied in viral myocarditis, viral enteritis, diabetic nephropathy, hepatitis, and sepsis in clinical in China [12-15]. For sepsis survivor treatment, clinical studies found that Astragalus injection could improve the patient immunity, such as regulating the levels of CD4/CD8 and inflammatory cytokines [14]. Animal studies further demonstrated that Astragalus injection or its active compound (Astragaloside IV, polysaccharides) could inhibit LPS-induced inflammation and NF-KB activation in mouse macrophages, and increase the integrality in endothelial cells [16-20]. Brain derived neurotropic factor (BDNF) is a major regulator of neural stem cell survival and differentiation, axon/dendrite differentiation [21], synapse formation and maturation, and refinement of developing circuits. Additionally, previous studies reported that Astragali Radix polysaccharides could improve the impaired learning and memory functions in aged rat via up-regulating the activity of hippocampal cAMP response element binding protein (CREB)/BDNF cascade [22].

Above all, even if the function of Astragalus injection and its active components on inflammation regulation, vascular permeability and memory consolidation improvement is mostly studied, it is unknown that whether it could ameliorate the post-sepsis cognitive impairment. Therefore, the present study is proposed to evaluate the benefit effects of Astragalus injection on post-sepsis cognitive decline and related mechanism. In a LPS-induced mice model of sepsis, our studies found that Astragalus injection could suppress the secretion of inflammatory cytokines (IL-1 $\beta$ and IL-6) and improve the integrality of BBB via up-regulation of tight junction proteins during acute stage after the LPS stimulus. What's more, novel object recognition test and morris water maze test reflected an improving recognition memory in Astragalus injection-treated mice, which is in line with their decreased neurodegeneration and 
up-regulated BDNF-CREB pathway in the hippocampus of mice during the chronic stage. Taken together, our data proved that Astragalus injection reverse acute BBB dysfunction and reduce neuroinflammation as well as up-regulate BDNF-CREB pathway during sepsis, preventing the development of long-term cognitive decline.

\section{Methods}

\section{Aim, design and setting of the study}

The aim of the present study is to evaluate the protective effects of Astragalus injection on the postsepsis cognitive impairment in mice and related mechanism. Besides, the design of the study as shown in Fig.1. Briefly, in a LPS-induced mice model of sepsis, the protective effects of Astragalus injection on post-sepsis cognitive impairment was first evaluated. Then the influence of Astragalus injection on inflammatory cytokines secretion, BBB integrality and tight junction proteins expression in the acute sepsis stage were studied later. Followed by the neurodegeneration analysis and BDNF-CREB pathway evaluation in the chronic sepsis stage. What's more, in vitro experiment was further conducted to assess the effects of Astragalus injection on inflammatory cytokines secretion in microglia (BV2 cells).

\section{Animals}

C57BL/6J male mice were purchased from the Experimental Animal Center of Chongqing Medical University (Certificate number SYXK, 2012-0001). All mice were housed, and bred in a climate-controlled environment at the animal facility of the Southwest University. All animal experiments were conducted in accordance with the National Institutes of Health guide for the care and use of Laboratory animals (NIH Publications No. 8023)

\section{Materials}

Astragalus injection was obtained from Chia Tai Tianqing Pharmaceutical Group Co., Ltd. (Hangzhou, China). LPS (from E. coli 0111:B4) was purchased from Sigma (MO, USA). Enzyme-linked immunosorbent assay (ELISA) kits for IL-1 $\beta$, TNF- $\alpha$ and IL- 6 were purchased from Boster Biological Technology (Wuhan, China). Rabbit polyclonal antibodies against zonula occludens-1 (ZO-1), clauidn-5 and occludin were purchased from Cell Signaling Technology Biotechnology (MA, USA). DyLight 649 (or DyLight 488)-conjugated donkey anti-rabbit or anti-goat antibodies were purchased from Boster Biological Technology (Wuhan, China). BV2 cell line (Passage 4) was purchased from Shanghai Guandao Bioengineering Co., Ltd (Shanghai, China).

\section{Animal treatments}

As Fig. 1 showed the scheme for in vivo experiments, C57BL/6J mice were injected with $5.0 \mathrm{ml} / \mathrm{kg}$ Astragalus injection (i.p., once a day) continuously for $18 \mathrm{~d} .2 .5 \mathrm{mg} / \mathrm{kg}$ LPS (i.p., once a day) was injected to mice at 4th and 5th day. For control and LPS group the Astragalus injection or LPS was replaced with saline. At 6 h, $48 \mathrm{~h}$ after the first administration of LPS, mice were euthanized, then blood and brain were 
isolated for further analysis. The novel object recognition test and morris water maze test were conducted at 7th and 10th day respectively. The mice were euthanized and brain were isolated for further analysis when behavior tests were finished.

\section{BV2 cells treatments}

For in vitro experiments (Fig 1, below), $1 \mu \mathrm{g} / \mathrm{ml}$ LPS was added directly into the culture medium after Astragalus injection $(5 \mu \mathrm{l} / \mathrm{ml})$ pre-incubation with BV2 cells for $2 \mathrm{~h}$. For secreted IL-1 $\beta$, TNF- $\mathrm{a}$ and IL-6 protein analysis, cell culture medium was collected at $6 \mathrm{~h}$ after adding LPS.

\section{Novel object recognition test}

At day 7-8, novel object recognition test was conducted on mice in each group based on the methods reported by our previous study [23]. Briefly, mice were individually placed in an empty open field for 5 min to explore and familiar with the open field the day before the test. $24 \mathrm{~h}$ later, two identical falcon tissue culture flasks were placed $5 \mathrm{~cm}$ away from the walls in the open field. Then the mice were individually placed in the open field, with head positioned opposite to the objects, and were allowed to behave freely for $10 \mathrm{~min}$. After the familiarization session, the mice were returned to their home cage. The objects and the open field were cleaned with 70\% ethanol. Six hours later, a novel object (Lego brick) was used to replace one of the two identical objects for the test session. The two objects were randomly placed at the same locations as in the familiarization session. Other procedures were not changed.

\section{Morris water maze}

From the 10th day, all mice were subjected to Morris water maze test. The protocol based on the report of our previous study [23] was used. First, 5 days of learning trials were performed, with 4 trials per day and $15 \mathrm{~s}$ of interval between each trial. The platform was located in the SW quadrant, $1 \mathrm{~cm}$ lower than the water level. Distal cues were available for assisting the mice to navigate to the hidden platform. A set of semirandomly start positions were applied. If a mouse failed to find the platform within $60 \mathrm{~s}$, it was picked up and placed on the platform for $15 \mathrm{~s}$. The time spent finding the hidden platform was recorded as escape latency. Twenty four hours after the last learning trial, a probe trial was administered to assess reference memory of the mice. The platform was removed in this trial. Mice were allowed to swim for $60 \mathrm{~s}$ in the pool, with NE quadrant as the start position. The crossing numbers on the location of the removed platform, and the time spent in the platform quadrant were recorded. Tab. 1 presents the start positions for the mice in the learning trials and the probe trial [24].

\section{Measurement of secreted IL-1 $\beta$, TNF- $\alpha$ and IL- 6 by ELISA}

IL-1 $\beta$, TNF- $\alpha$ and IL- 6 in blood, hippocampus and culture medium of BV2 cells were measured using commercially available ELISA kits. All incubation and washing steps were performed following the manufacturer recommended protocols. The optical density values were measured using a FlexStation 3 instrument. Cytokine levels were determined by comparison with the standard curve. 


\section{H\&E staining}

At $48 \mathrm{~h}$ after the first administration of LPS, mice brain were fixed in neutral buffered formalin were embedded in paraffin, cut into $5 \mu \mathrm{m}$-thick sections, and stained with H\&E according to a standard protocol.

\section{Evans blue perfusion analysis}

Evans blue perfusion analysis was performed as described previously [25]. At $48 \mathrm{~h}$ after the first administration of LPS, mice were intracardially perfused with prewarmed $0.9 \% \mathrm{NaCl}$ briefly to wash out blood cells, followed by $0.5 \%$ Evans blue in cold $4 \%$ paraformaldehyde. After perfusion, the brain was taken out, post-fixed in $4 \%$ paraformaldehyde at $4{ }^{\circ} \mathrm{C}$ for $4 \mathrm{~h}$, and then cryoprotected in 20 and $30 \%$ sucrose solutions in PBS at $4{ }^{\circ} \mathrm{C}$ for 3 days. The brain tissues were cut $30 \mu \mathrm{m}$ in thickness in a cryostat (Leica Microsystems, Wetzlar, Germany). Sections were mounted on gel-coated slides, dried at $37^{\circ} \mathrm{C}$ for 1 $\mathrm{h}$, and kept at $-20^{\circ} \mathrm{C}$ for use. The Evans blue-perfused cerebral microvessels in the sections, which exhibit fluorescence when the Evans Blue binds to proteins, were examined and imaged using a Leica fluorescence microscope equipped with a CCD camera (Leica Microsystems).

\section{Transmission electron microscopy analysis of tight junction}

Transmission electron microscopy analysis was performed as described previously[25]. At $48 \mathrm{~h}$ after the first administration of LPS, mice in each group were anesthetized and perfused transcardially with $2.5 \%$ glutaraldehyde in $0.1 \mathrm{M}$ PBS. Approximately $1 \mathrm{~mm} 3$ of the brain tissue was taken and fixed in freshly prepared $3 \%$ glutaraldehyde for $4 \mathrm{~h}$ at $4{ }^{\circ} \mathrm{C}$ and post-fixed in $1 \%$ osmium tetroxide for $2 \mathrm{~h}$. The specimens were then dehydrated through a graded series of ethanol $(50 \% \rightarrow 70 \% \rightarrow 80 \% \rightarrow 90 \% \rightarrow 95 \% \rightarrow 100 \%)$, and embedded in Epon 812 overnight. 60-80 nm ultrathin brain sections were obtained and stained with uranyl acetate and lead citrate. Sections were then examined using transmission electron microscopy (Hitachi-H7500, Japan).

\section{Immunohistochemistry}

Mice brain were fixed in freshly prepared $4 \%$ paraformaldehyde in PBS $(\mathrm{pH}=7.4)$ for $24 \mathrm{~h}$ at $4^{\circ} \mathrm{C}$. Then transfer to $20 \%$ sucrose-PBS ( $\mathrm{pH}=7.4$ ) until tissue submerges into the solution (about 24-36 h). The brain was then mounted into mounting medium and freeze on $-80^{\circ} \mathrm{C}$. After that the OTC-embedded brain was cut into $10 \mu \mathrm{m}$ sections via cryostat, and the sections were picked up with SuperFrost/Plus slides. Later, the sections were blocked in blocking buffer (0.3\% TritonX-100 in PBS) at room temperature for $2 \mathrm{~h}$. After that, primary antibodies against CD31 (1:100), ZO-1 (1:50), clauidn-5 (1:100) and occludin (1:100) were incubated with the sections overnight at $4{ }^{\circ} \mathrm{C}$. Secondary antibodies Dylight-488-conjugated donkey antirabbit and Dylight-649-conjugated donkey anti-goat secondary antibodies were then incubated with the sections in dark for $1 \mathrm{~h}$ at room temperature. Fluorescent images were acquired using Leica Sp2 confocal microscope. 


\section{Golgi staining}

3 mice brains per group were stained using a Golgi-staining kit following the manufacture's protocol (Servicebio, Wuhan, China). The brain tissue was submerged in Gorky's staining solution completely in a cool and ventilated place to avoid light for 14 days (After the first 48 hours of immersion, new staining solution was changed, and then the new staining solution was changed once every 3 days for a total of 14 days). Then transfer the tissue to $15 \%$ sucrose-PBS $(\mathrm{pH}=7.4)$ and dehydrate in dark for 1 day at $4{ }^{\circ} \mathrm{C}$. Later, the tissue was transferred to $30 \%$ sucrose-PBS $(\mathrm{pH}=7.4)$ and further dehydrate in dark for 2 days at $4{ }^{\circ} \mathrm{C}$. After that, the tissue was washed with distilled water for $1 \mathrm{~min}$, and then was immersed in concentrated ammonia water for $45 \mathrm{~min}$. Then the tissue was washed again with distilled water for $1 \mathrm{~min}$, and was immersed in acid film fixer for $45 \mathrm{~min}$. The Golgi-stained brains were sectioned to $100 \mu \mathrm{m}$ using a frozen microtome (Thermo, CRYOSTAR NX50). The sections were visualized under an upright microscope (NIKON ECLIPSE E100 microscope). For spine analysis, the dendrites in 20-30 $\mu \mathrm{m}$ lengths of the three tertiary segments were used to measure dendritic spine density via Image $\mathrm{J}$.

\section{Western blotting assays}

After the behavior test, the mice were sacrificed and brain was collected and hippocampus was separated from the mice. The hippocampus was homogenized in RIPA lysis buffffer and centrifuged at $12,000 \mathrm{~g}$ for $15 \mathrm{~min}\left(4^{\circ} \mathrm{C}\right)$. The supernatants were collected and were used for western blotting assay. Total protein concentration was measured by BCA protein assay method. $30 \mu \mathrm{g}$ of total protein was loaded onto SDSPAGE gels after being added with $5 \times$ sample buffffer and boiled at $95{ }^{\circ} \mathrm{C}$ for $10 \mathrm{~min}$. The separated proteins were then transferred on PVDF membranes and blocked with 5\% non-fat milk for $1 \mathrm{~h}$ at room temperature. The PVDF membranes with proteins were incubated with diluted primary antibodies at $4{ }^{\circ} \mathrm{C}$ overnight, including anti-TrkB (1:200), anti-p-TrkB(Y516) (1:200), anti-CaMKIla (1:200), anti-p-CaMKIla (Thr286, 1:200), anti-CREB1 (1:200), anti-p-CREB1 (Ser133) (1:500), anti-BDNF (1:500), and anti- $\beta$-actin $(1: 2000)$ antibodies. After washed with TBST for three times, the membranes were incubated with relative sources of secondary antibodies (1:10000) at room temperature for $2 \mathrm{~h}$. Finally, the protein bands were detected with immobilon western chemiluminescent HRP substrate (Millipore Sigma, USA). The images were analyzed with Image $J$. The signals of protein targets were normalized to $\beta$-actin.

\section{Data Statistics}

Data was drawn from at least three separate experiments performed in triplicate. The data were expressed as mean \pm SD and analyzed using SPSS version 19.0 statistical software. Comparisons between multiple groups were performed by one-way analysis of ANOVA followed by Tukey's Comparison Test. The escape latency in Morris water maze was analyzed with Repeated Measures ANOVA, followed by Tukey's Comparison Test. The exploration time in novel object recognition test, the platform crossing numbers and the time spent in platform quadrant in Morris water maze were analyzed with Kruskal-Wallis test followed by Mann-Whitney U test. P value $<0.05$ was considered significant. 


\section{Results}

\section{Astragalus injection improve mice recognition memory}

Behavioral test results showed that mice in LPS group had impaired cognitive function and the treatment of Astragalus injection ameliorated this impairment. Among novel object recognition test, results showed that the exploring time of one of the two same objects had no difffference in the familiarization session (Fig. 2A). However, during the test session, the LPS-treated mice showed shorter time spent on exploring the novel object than vehicle-treated mice $(\mathrm{P}<0.01$, Fig. 2B). Besides, the mice in Astragalus injection group spent more time on exploring the novel object than LPS-treated mice $(P<0.05$, Fig. 2B).

Morris water maze test results showed that mice in LPS group had longer escape latency than vehicletreated mice on the 5 th day during the five days' spatial learning period $(P<0.01$, Fig. $2 \mathrm{C})$. Meantime, mice in Astragalus injection group exhibited shorter escape latency on the 5th day when compared with LPS-treated mice $(P<0.05$, Fig. $2 C)$. Subsequently, the probe trial results showed that LPS-treated mice exhibite decreased platform crossings numbers $(P<0.05$, Fig. $2 D)$, as well as less time spent on the platform quadrant $(P<0.01$, Fig. $2 D)$ during the test period. However, Astragalus injection-treatment increased the platform crossing numbers $(P<0.05$, Fig. $2 E)$ and prolonged the swim time spent on platform quadrant $(P<0.05$, Fig. $2 E)$.

\section{Astragalus injection inhibition of IL-1 $\beta$ protein synthesis and secretion}

There is growing evidence that inhibiting inflammatory cytokines (such as IL-1 $\beta$ ) synthesis is a therapeutic strategy for the treatment of cognitive dysfunction induced by LPS in mice. Here, we investigated the effects of Astragalus injection on inflammatory cytokines (IL-1 $\beta$, TNF- $\alpha$ and IL-6) protein synthesis in vivo and in vitro. For animal experiment, pre-experiment showed that the protein levels of IL$1 \beta$, TNF- $\alpha$ and IL-6 peaked at $6 \mathrm{~h}$ in hippocampus after LPS administration to mice (Data was not shown). After 3 says of Astragalus injection pre-treatment $(5 \mathrm{ml} / \mathrm{kg})$, LPS ( $2.5 \mathrm{mg} / \mathrm{kg}$, i.p.) were administered, and the protein levels of inflammatory cytokines in hippocampus and blood were evaluated $6 \mathrm{~h}$ later by elisa. As Fig. 3A showed, compared with the control group, LPS could significantly induced the protein levels of IL-1 $\beta$, TNF- $\alpha$ and IL- 6 in hippocampus and blood. Besides, compared with the LPS group, except for the levels of TNF-a in blood, the protein levels of inflammatory cytokines in hippocampus and blood significantly declined in Astragalus injection group.

For microglia, LPS was added after Astragalus injection co-incubation with BV2 cells for $2 \mathrm{~h}$. And then the secretion of IL-1 $\beta$, TNF- $\alpha$ and IL- 6 proteins in the culture medium of BV2 cells were analysed $6 \mathrm{~h}$ later via elisa. Similar to the in vivo results, the protein levels of IL-1 $\beta$, TNF- $\alpha$ and IL- 6 in culture medium significantly increased after LPS stimulus (Fig. 3B). What's more, Astragalus injection could significantly decrease the IL-1 $\beta$ and IL-6 secretion in a dose-dependent manner (Fig. 3B, left and right). However, Astragalus injection showed no effects on LPS-induced TNF-a secretion (Fig. 3B, middle).

\section{Astragalus injection overcome LPS-induced neuroinflammation and blood brain barrier damage}


To further observe the effects of Astragalus injection on neuroinflammation and blood brain barrier structure, H\&E-stained of brain tissue, Evans blue perfusion and transmission electron microscopy analysis were conducted 24h later after the last administration of LPS (Fig. 1). As the hippocampus H\&Estaining results reflected, LPS induced axon pale staining on CA1 area, and the infiltration of lymphocytes can be found on the DG area (Fig. 4). What's more, Astragalus injection could ameliorate the above injury.

Evans blue is an azo dye, it can binds to albumin in blood and cannot traverse through normal BBB, whereas the structure-damaged BBB allowing it to passage. Therefore, the damage status of BBB structure can be reflected by the fluorescence intensity of evans blue in the cerebral slide. $24 \mathrm{~h}$ after the last dose of LPS, the mouse brain was conspicuously stained in blue, and the whole cerebral cortex was filled with robust fluorescent signals (Fig.5A). Besides, Astragalus injection markedly attenuated the blue staining in the mouse brain, as reflected by the fluorescent intensity of evans blue (Fig.5A). The ultrastructural changes of the BBB were also examined. As shown in control group, the BBB unit is composed of endothelial cells, basal lamina, pericytes, and astrocyte end feet (Fig. 5B). After the LPS injury, the basement membrane was disrupted and tight junctions were damaged, as well as evident swollen astrocyte end feet (Fig. 5B). However, in the Astragalus injection-treated group, the basement membrane was preserved and the tight junctions were restored (Fig. 5B).

\section{Astragalus injection improve the protein expression levels of tight junction proteins.}

The tight junction between brain microvascular endothelial cells is the fundamental structure of $\mathrm{BBB}$, the first barrier to maintain homeostasis of the cerebral microenvironment. The tight junction is composed of transmembrane proteins (encompassing occludin, claudin, and junction adhesion molecules), cytoplasmic attachment proteins (encompassing zonula occludens (ZO)-1, -2, and -3 proteins), and cytoskeleton protein F-actin. The expression levels of these proteins are closely relevant to the BBB functions.

As the above results showed that Astragalus injection could restore LPS-induced tight junctions damage in BBB. Subsequently, the tight junction proteins levels were further evaluated via immunofluorescence staining. CD31, a surface protein, is expressed ubiquitously within the vascular compartment and is located mainly at junctions between adjacent cells. Thus, it can be used as a marker for vascular or endothelial cells. The immunofluorescence double-labeling of CD31 and tight junction proteins (claudin-5, occludin and ZO-1) were conducted to confirm the protein expression levels of tight junction protein on microvascular endothelial cells.

Image from control group reflected the high expression of claudin-5, occludin and ZO-1 on on microvascular endothelial cells (Fig. 6-1, 2, 3). However, after the LPS injury, the green fluorescencelabeled that claudin-5, occludin and Z0-1 were detected only in a few vascular (Fig. 6-1, 2, 3). In addition, the green fluorescence of tight junction proteins (claudin-5, occludin and ZO-1) were enhanced in Astragalus injection group (Fig. 6-1, 2, 3).

\section{Astragalus injection prevents the neurodegeneration in the hippocampus}


It is known that neurodegeneration contribute to the deterioration of memory performance. As the above results showed that Astragalus injection could improve mice recognition memory, and then Golgi staining of hippocampus were conducted after the behavior tests to confirm its function on neurodegeneration of

LPS-treated mice. In serial coronal sections of the hippocampus, neurons in the LPS group had decreased complexity of dendritic trees, less dendritic branching, and reduced branch length in the hippocampal CA1 subfield compared to the control group, which was reversed by Astragalus injection treatment (Fig. 7A). What's more, significantly decreased dendritic spine density was observed in LPS-treated mice $(P<0.05$, Fig. 7B), which was restored by Astragalus injection ( $P<0.01$, Fig. 7B).

\section{Astragalus injection prevents the reduction of TrkB/CaMKIla/CREB/BDNF pathway associated proteins}

TrkB is a neurotropin receptor that binds brain-derived neurotropic factor (BDNF), and one of its downstream signaling transduction pathway is CaMKIla/CREB. Previous study found that CaMKIIa/CREB/BDNF pathway is coupled to the cognitive function. To confirm whether there was an association between improving recognition memory effects of Astragalus injection and tyrosine Kinase receptor B (TrkB)/CaMKIla/CREB/BDNF pathway, the protein expression of BDNF, TrkB, p-TrkB(Y516), CaMKIla, p-CaMKIla (Thr286), CREB1 and p-CREB1 (Ser133) in hippocampus were examined after the behavior tests via western blotting. Results showed that the LPS-treated mice had lower levels of hippocampal BDNF, TrkB, CaMKIla, CREB1 and p-CREB1 (Ser133) compared with group $(\mathrm{P}<0.05$, Fig. 8). However, the treatment of Astragalus injection showed positive effects and elevated the expression levels of the above proteins $(P<0.05$, Fig. 8$)$.

\section{Discussion}

In the present study, we show that LPS-induced sepsis in mice not only leads to systemic inflammatory and BBB dysfunction in acute stage, but also cause long-term consequence of cognitive behavioral deficits. Further studies discover that Astragalus injection could reverse the BBB dysfunction and reduce neuroinflammation, as well as prevent the neurodegeneration and up-regulate the BDNF-CREB pathway during LPS-induced sepsis, preventing the development of long-term cognitive decline. Taken together, our data suggested that Astragalus injection could be a valuable therapy strategy for sepsis survivors in clinical, as it can produce protect effects on the post-sepsis cognitive impairment from many target spots and stages.

More and more evidences support that inflammation and neurodegeneration are related events. A large amount of reactive oxygen species, cytokines and nitric oxide are produced when leucocytes (especially macrophages) response to gram-negative bacteria infection in the pathogenesis of septic shock. Inflammatory cytokines, liberated from macrophages, could directly activate microglia in brain, which in turn produce pro-inflammatory cytokines and result in neuron injury $[4,6,26]$. A recent research indicated that the aged mice with decreased methylation of the IL-1 $\beta$ gene promoter in microglia which is associated with increased intracellular IL-1 $\beta$ production, as well as prolonged sickness behavior after LPS injury [8]. Another research also showed that minocycline could improve long-term cognitive impairment 
in sepsis survivors via decreasing acute brain oxidative damage and inflammation [27]. Similarly, Patricia et al. reported that statins could prevent cognitive impairment after sepsis by reverting neuroinflammation, and microcirculatory [28]. In line with previous findings, the present study observed a cause-and-effect relationship between Astragalus injection decreaseing the protein levels of TNF- $a$, IL-1 $\beta$ and IL- 6 and ameliorating the neurodegeneration in the hippocampus. Interestingly, even no influence of Astragalus injection was observed on the liberation of TNF- $a$ in blood and BV2 cells, the TNF-a levels in hippocampus in Astragalus injection-treated mice was significantly lower than that in LPS group. The reason for the above phenomenon may be the dysfunction of BBB integrity, since the inflammatory mediators could gain access to the brain parenchyma in sepsis through the impaired BBB.

The BBB is a major internal barrier between the peripheral circulation and the central nervous system, and it strictly restricts the transport of substances that are neurotoxic to protect the central nervous system. It comprises of brain microvascular endothelial cells, pericytes, astrocytic end-feet, basal laminar, neurons, and microglia. Among them, the tight junction between brain microvascular endothelial cells is the fundamental structure of BBB, the first barrier to maintain homeostasis of the cerebral microenvironment. It is well established that LPS induced-system inflammation could disrupt the integrity and function of BBB $[2,10]$. Nishioku et al. reported that pericyte detachment and microglial activation may be involved in the mediation of LPS induced-BBB disruption due to the inflammatory responses in the damaged brain [29]. Our previous in vitro study revealed that LPS destructed the integrity between mice brain microvascular endothelial cells via disaggregating cytoskeleton actin and down-regulating tight junctional proteins, such as claudin-5, occludin, and ZO-1, as well as increasing the secretion of endothelin-1 and inflammatory cytokines secretion [25]. In consistent with our previous results, the disrupted ultrastructure of BBB and the down-regulation of tight junctional proteins were observed in mice after the LPS injury. However, Astragalus injection could reverse the above injury, suggesting that the translocation of inflammatory cytokines into BBB could be inhibited, thus the microglia activation and related neuron injury would be ameliorated partly.

A recent review summarized that BDNF is involved in the formation of different types of memories and is also critical for maintaining long-lasting storage of information in hippocampus [30]. It is the same as one report showed that hippocampus-specific deletion of BDNF in adult mice impairs spatial memory and extinction of aversive memories [31]. BDNF binds to its high-affifinity receptor TrkB triggering the activation of one or more of three major signaling pathways, such as CaMKIlla, phosphatidylinositol 3kinase (PI3K), phospholipase C gamma (PLC- $\gamma$ ) and extracellular signal-regulated kinase 1/2 (ERK1/2), regulating certain forms of synaptic plasticity including long-term potentiation and effecting synaptic transmission [32-35]. Our results discovered that Astragalus injection could up-regulate BDNF expression and activate its downstream pathways TrkB/CaMKIla/CREB, which may contribute to the improving of spatial learning novel object recognition as well as spatial learning in the water maze. An component analysis for Astragalus injection reflected that in 246 batches of samples, the weight average molecular weight of polysaccharide is between 7684 and 108846, and the molecular weight distribution width is between 0.89 and 2.71 [36]. As previous studies discovered that Astragali Radix polysaccharides could improve the impaired learning and memory functions in aged rat via up-regulating the activity of 
hippocampal CREB/BDNF cascade (Yao et., 2014). It is then speculated that Astragali Radix polysaccharides may be the main active ingredients in Astragalus injection which account for upregulating TrkB/CaMKIla/CREB pathway and then improving the cognitive impairment.

\section{Conclusions}

The present study suggested that Astragalus injection could be used in the prevention and treatment of post-sepsis cognitive impairment, as its benefits on inflammatory inhibition, BBB integrity maintaining, and neurotrophic factor up-regulation in different stage.

\section{Abbreviations}

BBB, blood-brain barrier; BDNF, Brain derived neurotropic factor; CLP, Cecal ligation and puncture; CREB, CAMP response element binding protein; extracellular signal-regulated kinase 1/2 (ERK1/2); IL-1, interleukin-1; LPS, Lipopolysaccharide; phosphatidylinositol 3-kinase (PI3K); phospholipase $\mathrm{C}$ gamma (PLC-y); TNF-a, tumor necrosis factor-a; tyrosine Kinase receptor B (TrkB); ZO-1, zonula occludens-1.

\section{Declarations}

\section{Authors' contributions}

Huifeng Zhu' ${ }^{1 \#}$, Ke Liu ${ }^{1 \#}$, Ruhong Jiang ${ }^{2}$, Guoran Wan ${ }^{3}$, Li Zou ${ }^{1}$, Xiaokang Zhu' ${ }^{1}$, Qiao Ren ${ }^{1}$, Dong Wan ${ }^{4}$, Fang Cheng ${ }^{5 *}$, Shan Feng

$\mathrm{HFZ}, \mathrm{KL}, \mathrm{RHJ}, \mathrm{GRW}, \mathrm{LZ}$, and SF performed the in vitro and in vivo experiments and analyzed the data. HFZ and SF wrote the manuscript. QR XKZ and FC revised the manuscript. HFZ, DW, FC and SF conceived the original idea and designed the experiments for this study. All authors read and approved the final manuscript.

\section{Ethics approval and consent to participate}

Procedures were approved by the Chinese Institutional Animal Care Committee of Southwest University. Consent to participate is not applicable.

\section{Consent for publication}

Not applicable.

\section{Availability of data and materials}

The datasets analyzed during the current study are available from the corresponding author upon reasonable request. 
The authors declare that they have no competing interests.

\section{Funding}

This study was funded by National Natural Science Foundation of China (NSFC) (NSFC-81903817, -81873034 and 21602180); Chongqing Research Program Basic Research and Frontier Technology (cstc2017jcyjAX0137); Fundamental Research Funds for the Central Universities (XDJK2017D154, XDJK2019C113); China Postdoctoral Science Foundation (2016M602641), Postdoctoral Foundation of Southwest University (102060-20750902); Special Subject Program Foundation of TCM Science Research of Henan Province (2018ZY2010 and 2019ZY1023).

\section{Acknowledgements}

The authors appreciated the technical assistance of Professor Weihai Chen in the department of psychology of Southwest University.

\section{References}

[1] Fleischmann C, Scherag A, Adhikari NK, et al. Assessment of Global Incidence and Mortality of Hospital-treated Sepsis. Current Estimates and Limitations. Am J Respir Crit Care Med 2016; 193(3): 25972.

[2] Danielski LG, Giustina AD, Badawy M, Barichello T, Quevedo J, Dal-Pizzol F, Petronilho F. Brain Barrier Breakdown as a Cause and Consequence of Neuroinflammation in Sepsis. Mol Neurobiol. 2018;55(2):1045-1053.

[3] Schwalm MT, Pasquali M, Miguel SP, Dos Santos JP, Vuolo F, Comim CM, Petronilho F, Quevedo J, Gelain DP, Moreira JC, Ritter C, Dal-Pizzol F. Acute brain inflammation and oxidative damage are related to long-term cognitive deficits and markers of neurodegeneration in sepsis-survivor rats.Mol Neurobiol. 2014; 49(1):380-385.

[4] Hoogland ICM, Westhoff D, Engelen-Lee JY, Melief J, Valls Serón M, Houben-Weerts JHMP, Huitinga I, van Westerloo DJ, van der Poll T, van Gool WA, van de Beek D. Microglial Activation After Systemic Stimulation With Lipopolysaccharide and Escherichia coli.Front Cell Neurosci. 2018;12:110.

[5] Henry CJ, Huang Y, Wynne AM, Godbout JP. Peripheral lipopolysaccharide (LPS) challenge promotes microglial hyperactivity in aged mice that is associated with exaggerated induction of both proinflammatory IL-1 $\beta$ and anti-inflammatory IL-10 cytokines. Brain Behav Immun. 2009; 23(3):309-317. 
[6] Michels M, Danielski LG, Dal-Pizzol F, Petronilho F. Neuroinflammation: Microglial Activation During Sepsis. Curr Neurovasc Res. 2014; 11(3): 262-270.

[7] Rose-Marie B, Sophie L, Bruno M, Chantal C, Robert D, Patricia P. Role of interleukin-1b and tumour necrosis factor-a in lipopolysaccharide-induced sickness behaviour: a study with interleukin-1 type I receptor-deficient mice. European Journal of Neuroscience. 2000; 12: 4447-4456.

[8] Matt SM, Lawson MA, Johnson RW. Aging and peripheral lipopolysaccharide can modulate epigenetic regulators and decrease IL-1 $\beta$ promoter DNA methylation in microglia. Neurobiol Aging. 2016; 47:1-9.

[9] Nishioku T, Dohgu S, Takata F, Eto T, Ishikawa N, Kodama KB, Nakagawa S, Yamauchi A, Kataoka Y. Detachment of Brain Pericytes from the Basal Lamina is Involved in Disruption of the Blood-Brain Barrier Caused by Lipopolysaccharide-Induced Sepsis in Mice. Cell Mol Neurobiol. 2009; 29(3):309-316.

[10] Banks WA, Gray AM, Erickson MA, Salameh TS, Damodarasamy M, Sheibani N, Meabon JS, Wing EE, Morofuji Y, Cook DG, Reed MJ. Lipopolysaccharide-induced blood-brain barrier disruption: roles of cyclooxygenase, oxidative stress, neuroinflammation, and elements of the neurovascular unit. J Neuroinflammation. 2015;12:223.

[11] Chi JM, Mackay M, Hoang A, Cheng K, Aranow C, Ivanidze J, Volpe B, Diamond B, Sanelli PC. Alterations in Blood-Brain Barrier Permeability in Patients with Systemic Lupus Erythematosus. AJNR Am J Neuroradiol. 2019; 40(3):470-477.

[12] Yu H, Hu Q, Sun J, Feng R, Zhang S, Zhang J, Mao XH, Ji S. Comprehensive Screening of Multicomponents in Huangqi Injection by Ultra-performance Liquid Chromatography Coupled with Quadrupoletime-of-flight Mass Spectrometry. World Chinese Medicine. 2019;14(4): 809-817.

[13] Chen YB. Influence of Radix Astragali injection on imminologic function in septic patients. Medicine school of Zejiang University. 2008.

[14] Wu SX. The study of clinical effect of Astragalus injection treating critical sepsis patients. Guangzhou University of Chinese Medicine. 2013.

[15] Wang MS, Li J, Di HX, Li ZL, Yang SL, Hou W, Yan JY, Zhao XM. Clinical study on effect of Astragalus Injection and its immuno-regulation action in treating chronic aplastic anemia. Chin J Integr Med. 2007;13(2):98-102.

[16] Zhao P, Wang Y, Zeng S, Lu J, Jiang TM, Li YM. Protective effect of astragaloside IV on lipopolysaccharide-induced cardiac dysfunction via downregulation of inflammatory signaling in mice. Immunopharmacol Immunotoxicol. 2015;37(5):428-433.

[17] Li L, Hou X, Xu R, Liu C, Tu M. Research review on the pharmacological effects of astragaloside IV. Fundam Clin Pharmacol. 2017;31(1):17-36. 
[18] Zhou X, Sun X, Gong X, Yang Y, Chen C, Shan G, Yao Q. Astragaloside IV from Astragalus membranaceus ameliorates renal interstitial fibrosis by inhibiting inflammation via TLR4/NF-KB in vivo and in vitro.Int Immunopharmacol. 2017;42:18-24.

[19] Yang J, Wang HX, Zhang YJ, Yang YH, Lu ML, Zhang J, Li ST, Zhang SP, Li G. Astragaloside IV attenuates inflammatory cytokines by inhibiting TLR4/NF-KB signaling pathway in isoproterenol-induced myocardial hypertrophy. J Ethnopharmacol. 2013;150(3): 1062-1070.

[20] Leng B, Tang F, Lu M, Zhang Z, Wang H, Zhang Y. Astragaloside IV improves vascular endothelial dysfunction by inhibiting the TLR4/NF-KB signaling pathway. Life Sci. 2018; 209:111-121.

[21] Heldt, S.A., Stanek, L., Chhatwal, J.P., Ressler, K.J., 2007. Hippocampus-specifific deletion of BDNF in adult mice impairs spatial memory and extinction of aversive memories. Mol. Psychiatry 12, 656e670.

[22] Yao H, Gu LJ, Guo JY. Study on effect of astragali radix polysaccharides in improving learning and memory functions in aged rats and its mechanism. Zhongguo Zhong Yao Za Zhi. 2014 Jun;39(11):20712075.

[23] Tang Q, Ke H, Wu C, Zeng J, Li Z, Liu Y, Feng S, Xue Q, Xu X. Aqueous extract from You-Gui-Yin ameliorates cognitive impairment of chronic renal failure mice through targeting hippocampal CaMKIIa/CREB/BDNF and EPO/EPOR pathways. J Ethnopharmacol. 2019; 239:111925.

[24] Vorhees CV, Williams MT. Morris water maze: procedures for assessing spatial and related forms of learning and memory. Nat Protoc. 2006;1(2):848-858.

[25] Feng S, Zou L, Wang H, He R, Liu K, Zhu H. RhoA/ROCK-2 Pathway Inhibition and Tight Junction Protein Upregulation by Catalpol Suppresses Lipopolysaccaride-Induced Disruption of Blood-Brain Barrier Permeability. Molecules. 2018; 23(9). pii: E2371.

[26] Hoogland IC, Houbolt C, van Westerloo DJ, van Gool WA, van de Beek D. Systemic inflammation and microglial activation: systematic review of animal experiments. J Neuroinflammation. 2015;12:114.

[27] Hoshino K, Hayakawa M, Morimoto Y. Minocycline Prevents the Impairment of Hippocampal LongTerm Potentiation in the Septic Mouse. Shock. 2017; 48(2):209-214.

[28] Reis PA, Alexandre PCB, D'Avila JC, Siqueira LD, Antunes B, Estato V, Tibiriça EV, Verdonk F, Sharshar T, Chrétien F, Castro-Faria-Neto HC, Bozza FA. Statins prevent cognitive impairment after sepsis by reverting neuroinflammation, and microcirculatory/endothelial dysfunction. Brain Behav Immun. 2017;60:293-303.

[29] Nishioku T, Dohgu S, Takata F, Eto T, Ishikawa N, Kodama KB, Nakagawa S, Yamauchi A, Kataoka Y. Detachment of brain pericytes from the basal lamina is involved in disruption of the blood-brain barrier caused by lipopolysaccharide-induced sepsis in mice.Cell Mol Neurobiol. 2009; 29(3):309-316. 
[30] Kozisek ME, Middlemas D, Bylund DB. Brain-derived neurotrophic factor and its receptor tropomyosinrelated kinase $B$ in the mechanism of action of antidepressant therapies.Pharmacol Ther. 2008; 117(1):30-51.

[31] Heldt SA, Stanek L, Chhatwal JP, Ressler KJ. Hippocampus-specific deletion of BDNF in adult mice impairs spatial memory and extinction of aversive memories. Mol Psychiatry. 2007;12(7):656-670.

[33] Xenos D, Kamceva M, Tomasi S, Cardin JA, Schwartz ML, Vaccarino FM. Loss of TrkB Signaling in Parvalbumin-Expressing Basket Cells Results in Network Activity Disruption and Abnormal Behavior. Cereb Cortex. 2018;28(10):3399-3413.

[34] Koike H, Fukumoto K, lijima M, Chaki S. Role of BDNF/TrkB signaling in antidepressant-like effects of a group II metabotropic glutamate receptor antagonist in animal models of depression. Behav Brain Res. $2013 ; 238: 48-52$.

[35] Adachi M, Autry AE, Mahgoub M, Suzuki K, Monteggia LM. TrkB Signaling in Dorsal Raphe Nucleus is Essential for Antidepressant Efficacy and Normal Aggression Behavior. Neuropsychopharmacology. 2017; 42(4):886-894.

[36] Jian LH, Xia J, Shen YY, Lin J, Wang K, Ji S. Study of relative molecular mass of polusaccharides in huangqi injection by high performance gelpermeation chromatography. Chin J Pharm Anal. 2010; 30(11): 2037-2039.

\section{Tables}

\section{Tab. 1. Morris water maze spatial (hidden platform) start positions}

\section{Acquisition}

\begin{tabular}{ccccc}
\hline Day & Trial 1 & Trial 2 & Trial 3 & Trial 4 \\
1 & $\mathrm{~N}$ & $\mathrm{E}$ & $\mathrm{SE}$ & $\mathrm{NW}$ \\
2 & $\mathrm{SE}$ & $\mathrm{N}$ & $\mathrm{NW}$ & $\mathrm{E}$ \\
3 & $\mathrm{NW}$ & $\mathrm{SE}$ & $\mathrm{E}$ & $\mathrm{N}$ \\
4 & $\mathrm{E}$ & $\mathrm{NW}$ & $\mathrm{N}$ & $\mathrm{SE}$ \\
5 & $\mathrm{~N}$ & $\mathrm{SE}$ & $\mathrm{E}$ & $\mathrm{NW}$ \\
6 (Probe) & $\mathrm{NE}$ & & & \\
\hline
\end{tabular}


N, north. E, east. SE, south east. NW, north west. NE, north east. Referenced from [24].

\section{Figures}

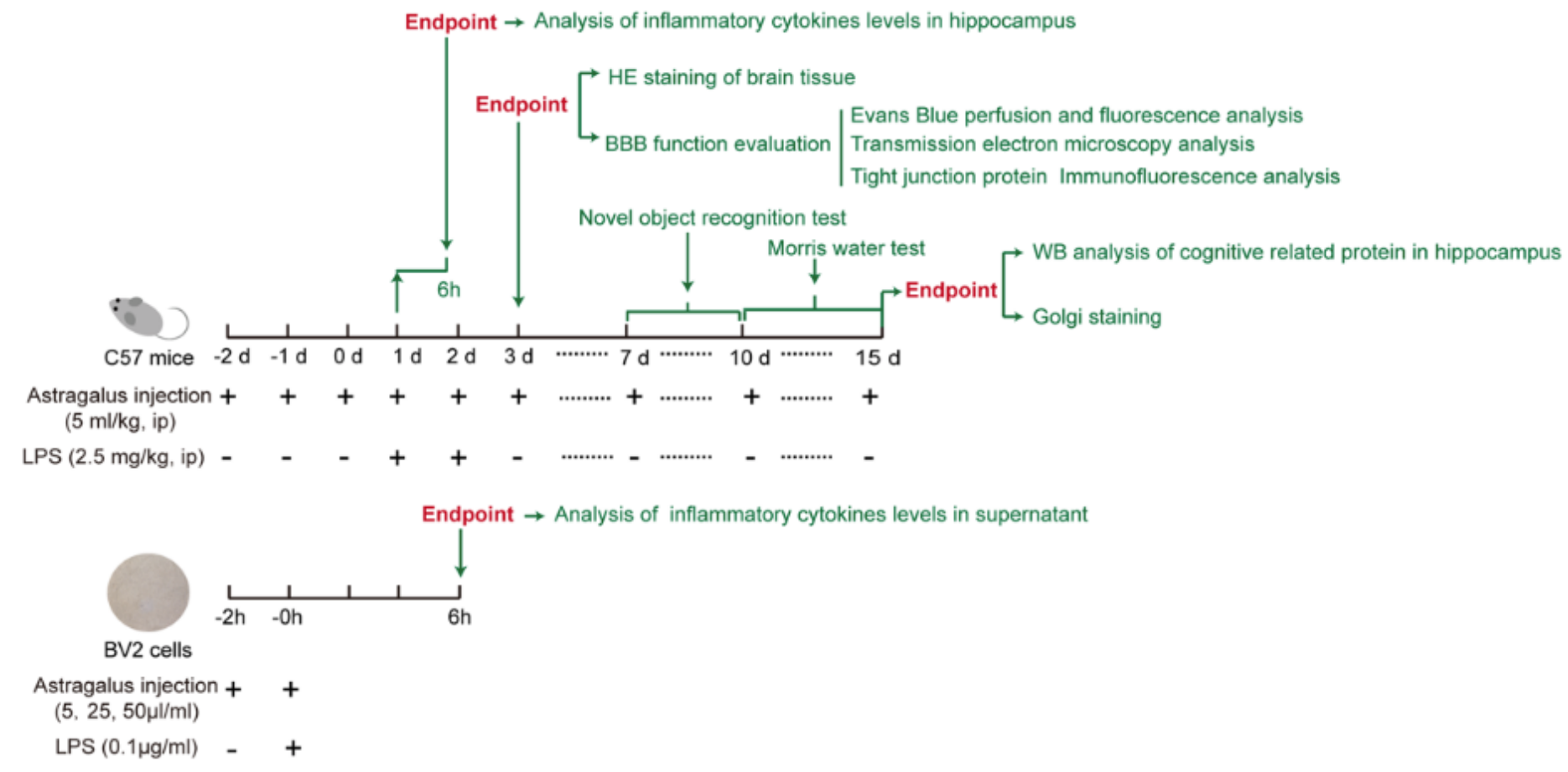

\section{Figure 2}

The study design of Astragalus injection ameliorate Lipopolysaccaride-induced cognitive decline and Blood-Brain Barrier Permeability Disruption. in vivo (top) and in vitro (bottom). 

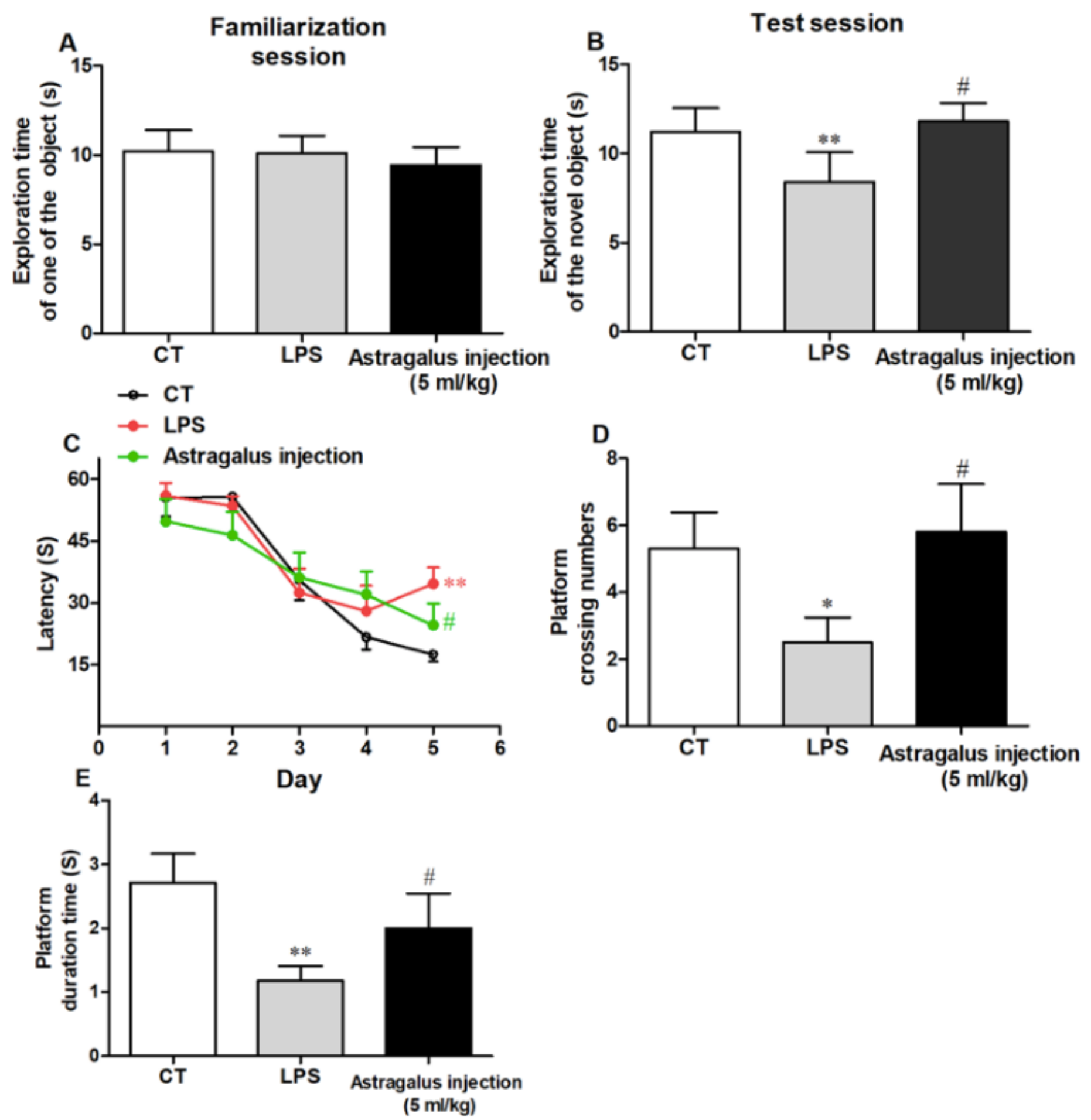

Figure 4

Effects of Astragalus injection on improving mice recognition memory shown by novel object recognition test ( $A$ and $B$ ) and morris water maze test ( $C, D$ and $E$ ). (A) Exploration time of one of the two identical objects in the familiarization session; (B) Exploration time of the novel object in the test session; (C) Escape latency in the five day's acquisition trials; (D) Platform crossing numbers in the probe trial; $(E)$ 
Time spent in platform quadrant in the probe trial; Values are presented as means $\pm S D(n=10)$. ${ }^{\star \star} p<$ 0.01 vs. the LPS group; \#p < 0.05, vs. the model group. CT, Control. LPS, Lipopolysaccharide.
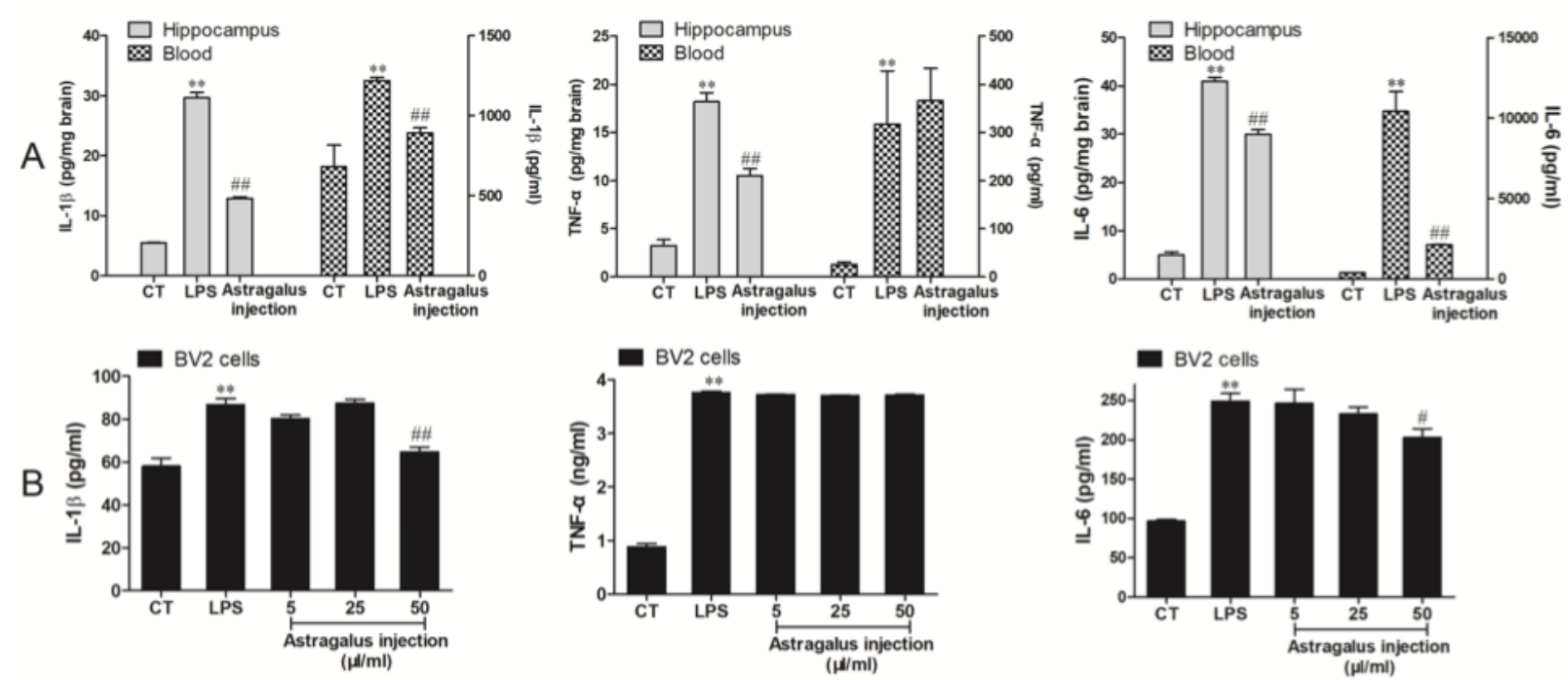

Figure 6

Astragalus injection improved LPS-induced IL-1 $\beta$, TNF- $\alpha$ and IL- 6 protein synthesis and secretion. A, LPS $(2.5 \mathrm{mg} / \mathrm{kg})$ were administrated to mice after Astragalus injection $(5 \mathrm{mg} / \mathrm{kg}$ per day, ip) pre-treatment for three days, and the inflammatory cytokines in mice hippocampus (left, plot on left $Y$ axis) and blood (right, plot on right $Y$ axis) were evaluated $6 \mathrm{~h}$ later. B, Cultured BV2 cells were treated with LPS $(1 \mu \mathrm{g} / \mathrm{ml}$ in culture medium) for $6 \mathrm{~h}$ after pre-incubation with Astragalus injection for $2 \mathrm{~h}$. Values are presented as means $\pm S D(n=6) .{ }^{*} p<0.01$ vs. the control group; $\# p<0.05$, \#\#p<0.01,vs. the LPS group. CT, Control. LPS, Lipopolysaccharide. 


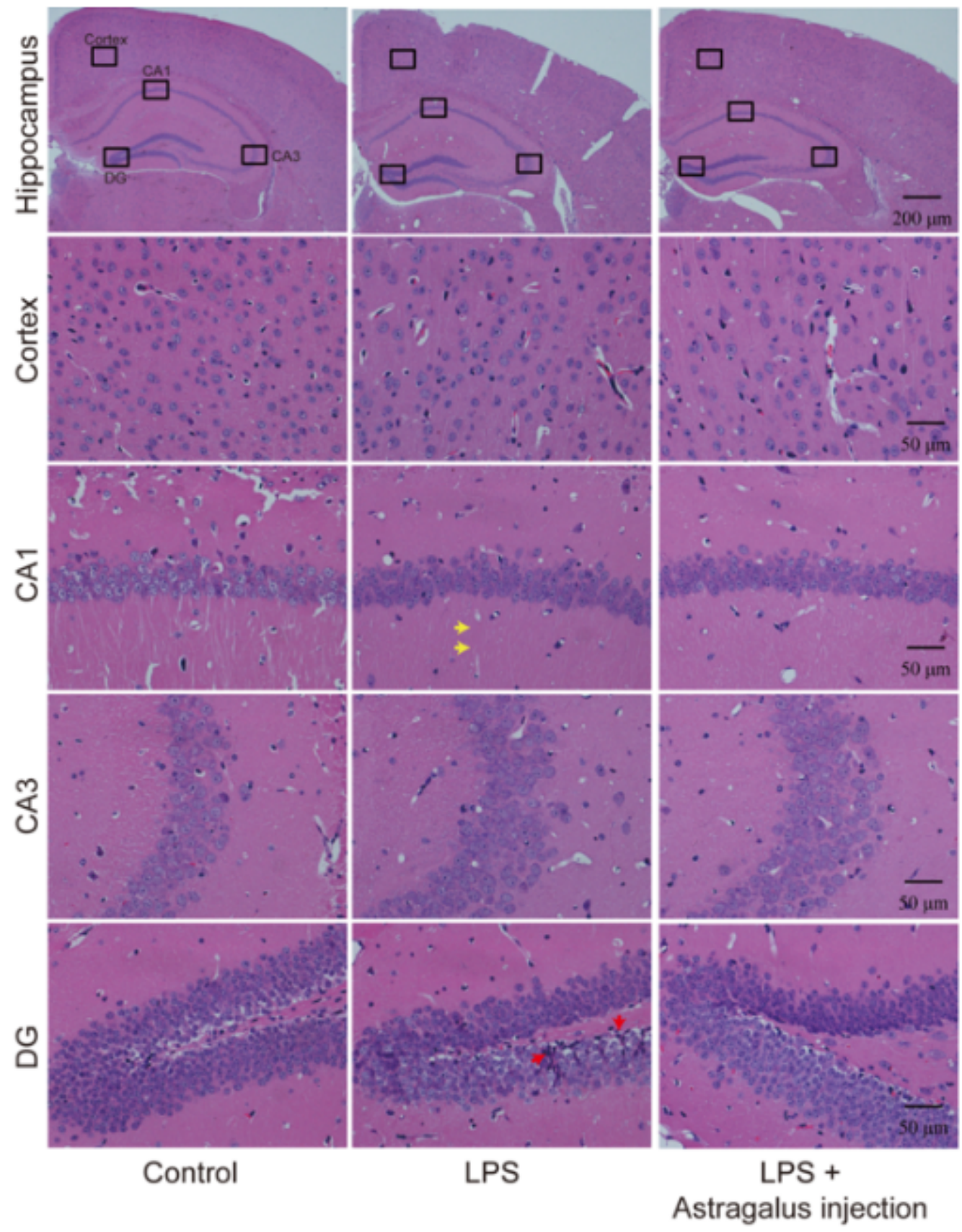

\section{Figure 7}

Astragalus injection improved the brain histopathological changes in mice (Revealed by the H\&E-stained brain sections). LPS, mice given a series intraperitoneal injection of $2.5 \mathrm{mg} / \mathrm{kg}$ LPS dissolved in sterile normal saline at 1 and 2 day. LPS + Astragalus injection, Before administration of LPS, mice were given 5 $\mathrm{ml} / \mathrm{kg}$ Astragalus injection (ip), once a day for 3 days. Yellow arrows indicate the axon pale staining; Red arrows indicate the infiltration of lymphocytes. CT, Control. LPS, Lipopolysaccharide. DG, Dentate gyrus. CA, Cornu ammonis. 

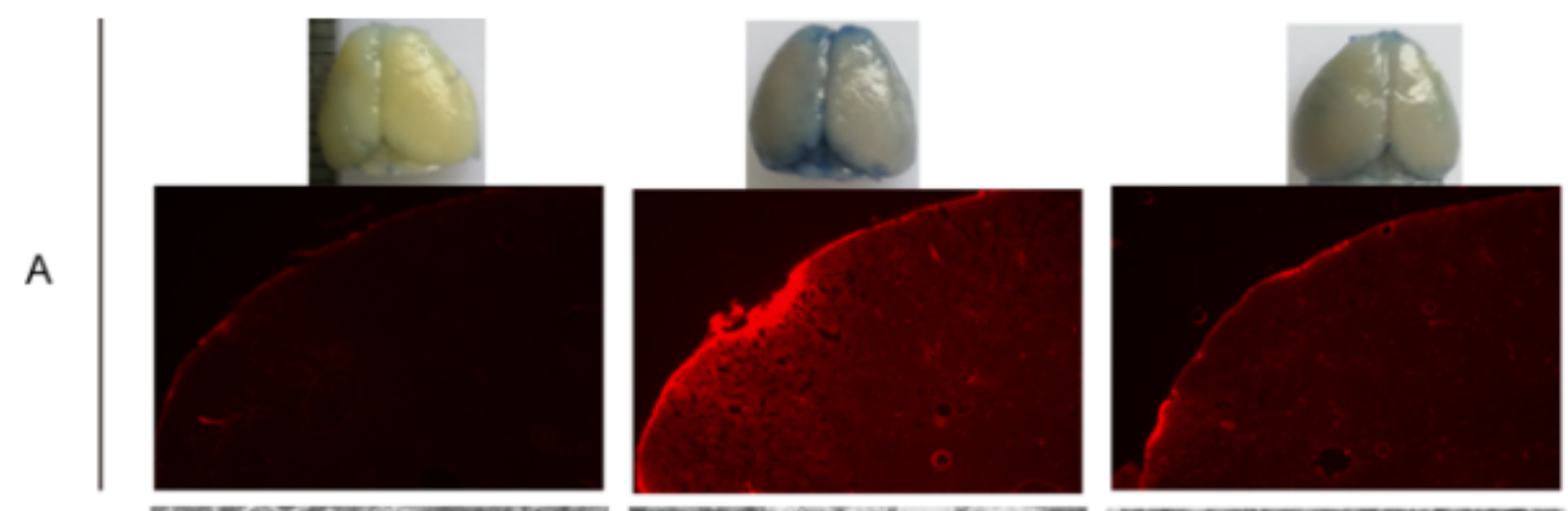

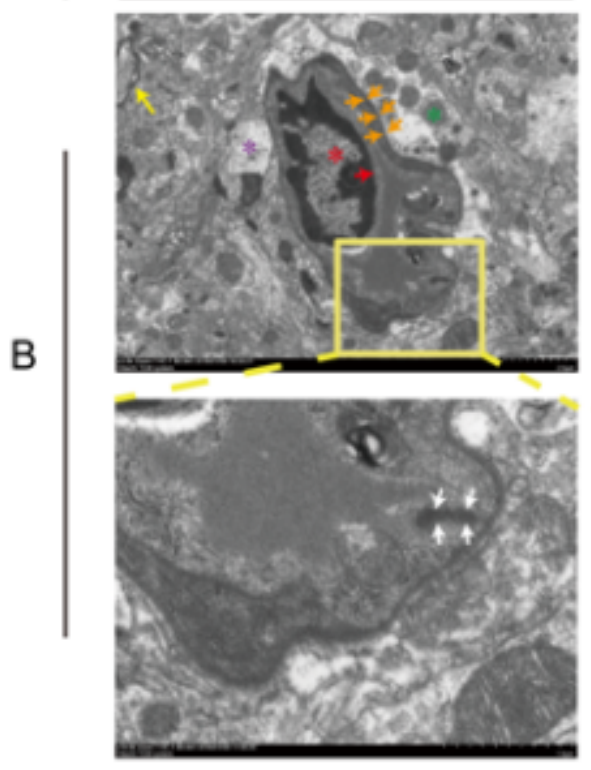

Control
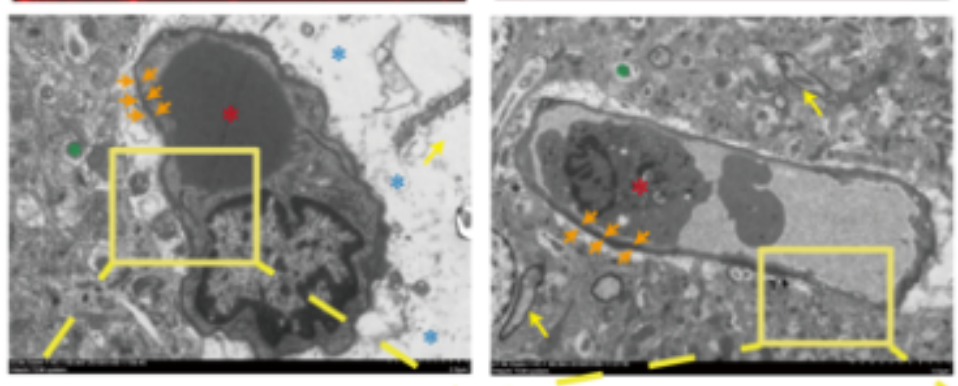

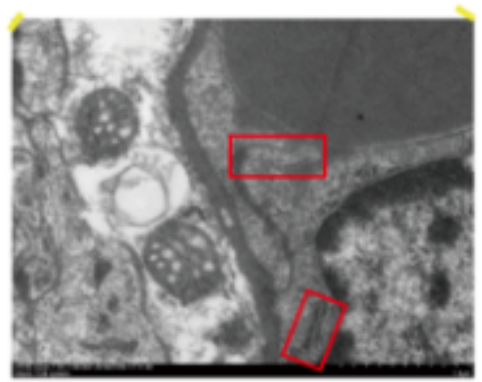

LPS

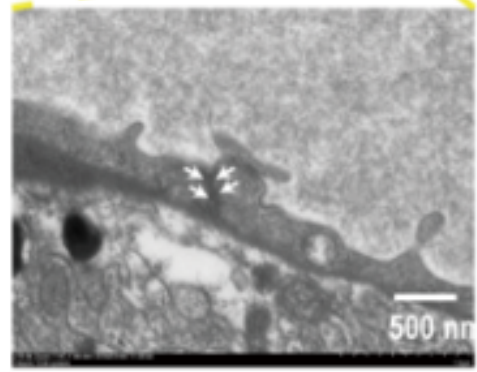

Astragalus injection

$(5 \mathrm{ml} / \mathrm{kg})$

\section{Figure 9}

Astragalus injection improved LPS-induced BBB damage. (A) EB leakage in brain tissue. *, the cerebral cortex was filled with robust fluorescent signals. (B) the ultrastructural changes of the BBB. Red asterisks indicate the vessel; Red arrows indicate the endothelial cells; Orange arrows indicate the basal lamina; Purple asterisks indicate the astroglial end feet; Green asterisks indicate the axon or dendrite; Yellow arrows indicate the myelin sheath; Blue asterisks indicate the swollen astroglial end feet; White arrows indicate the tight junction; Red panels indicate the detached tight junction. LPS, mice given a series intraperitoneal injection of $2.5 \mathrm{mg} / \mathrm{kg}$ LPS dissolved in sterile normal saline at 1 and 2 day. LPS + Astragalus injection, Before administration of LPS, mice were given $5 \mathrm{ml} / \mathrm{kg}$ Astragalus injection (ip), once a day for 3 days. CT, Control. LPS, Lipopolysaccharide. 

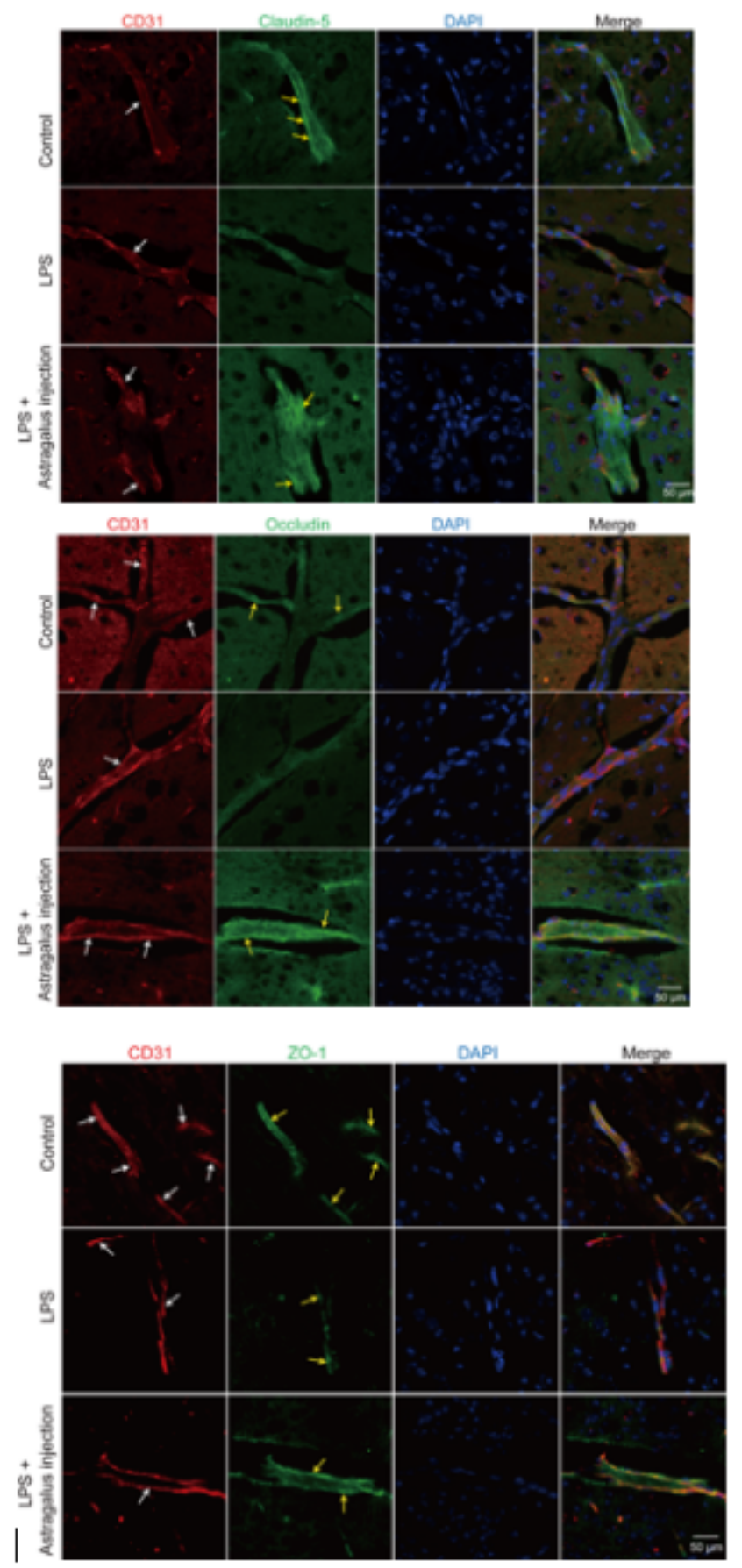

\section{Figure 12}

Fig. 6-1. The effects of Astragalus injection on claudin-5 decreased expression induced by LPS detected by immunofluorescence staining. White arrows indicate the capillary (CD31 positive staining indicate vascular endothelial cell); Yellow arrows indicate the positive staining of claudin-5. LPS, mice given a series intraperitoneal injection of $2.5 \mathrm{mg} / \mathrm{kg}$ LPS dissolved in sterile normal saline at 1 and 2 day. LPS + Astragalus injection, Before administration of LPS, mice were given $5 \mathrm{ml} / \mathrm{kg}$ Astragalus injection (ip), once a day for 3 days. CT, Control. LPS, Lipopolysaccharide. Fig. 6-2. The effects of Astragalus injection on occludin decreased expression induced by LPS detected by immunofluorescence staining. White arrows indicate the capillary (CD31 positive staining indicate vascular endothelial cell); Yellow arrows 
indicate the positive staining of occludin. LPS, mice given a series intraperitoneal injection of $2.5 \mathrm{mg} / \mathrm{kg}$ LPS dissolved in sterile normal saline at 1 and 2 day. LPS + Astragalus injection, Before administration of LPS, mice were given $5 \mathrm{ml} / \mathrm{kg}$ Astragalus injection (ip), once a day for 3 days. CT, Control. LPS, Lipopolysaccharide. Fig. 6-3. The effects of Astragalus injection on ZO-1 decreased expression induced by LPS detected by immunofluorescence staining. White arrows indicate the capillary (CD31 positive staining indicate vascular endothelial cell); Yellow arrows indicate the positive staining of ZO-1. LPS, mice given a series intraperitoneal injection of $2.5 \mathrm{mg} / \mathrm{kg}$ LPS dissolved in sterile normal saline at 1 and 2 day. LPS + Astragalus injection, Before administration of LPS, mice were given $5 \mathrm{ml} / \mathrm{kg}$ Astragalus injection (ip), once a day for 3 days. CT, Control. LPS, Lipopolysaccharide.

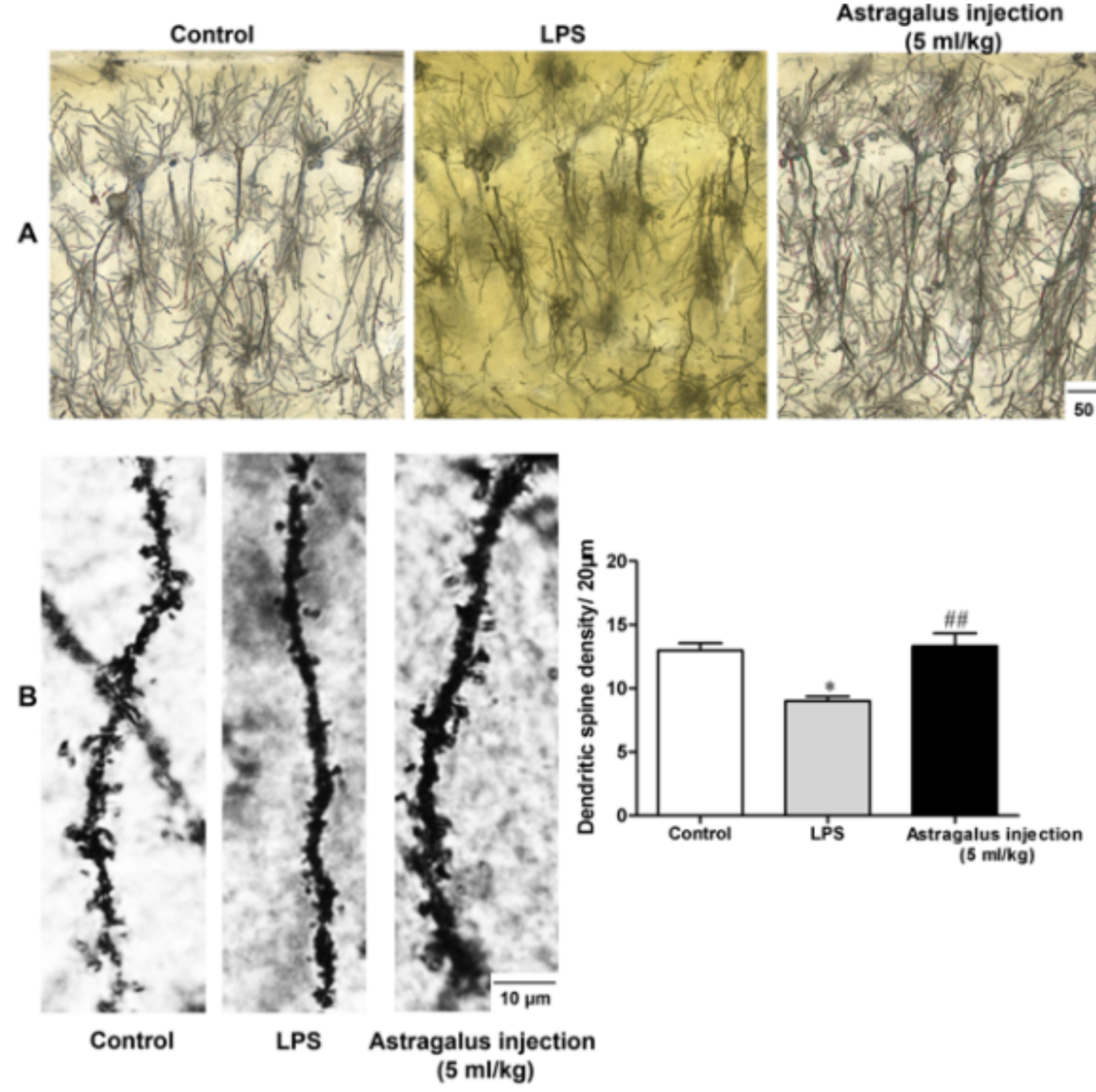

\section{Figure 14}

Astragalus injection prevented the neurodegeneration in the hippocampus of LPS-exposed mice. (A) Golgi silver-stained neurons in the hippocampal CA1 subfield. Bar $=50 \mu \mathrm{m}$. (B) Representative dendritic spine and dendritic spine density at the CA1 hippocampal region $(n=9-13)$. Bar $=10 \mu \mathrm{m}$. ${ }^{*} p<0.05 \mathrm{vs}$. the control group; \#\#p<0.01, vs. the LPS group. CT, Control. LPS, Lipopolysaccharide. 

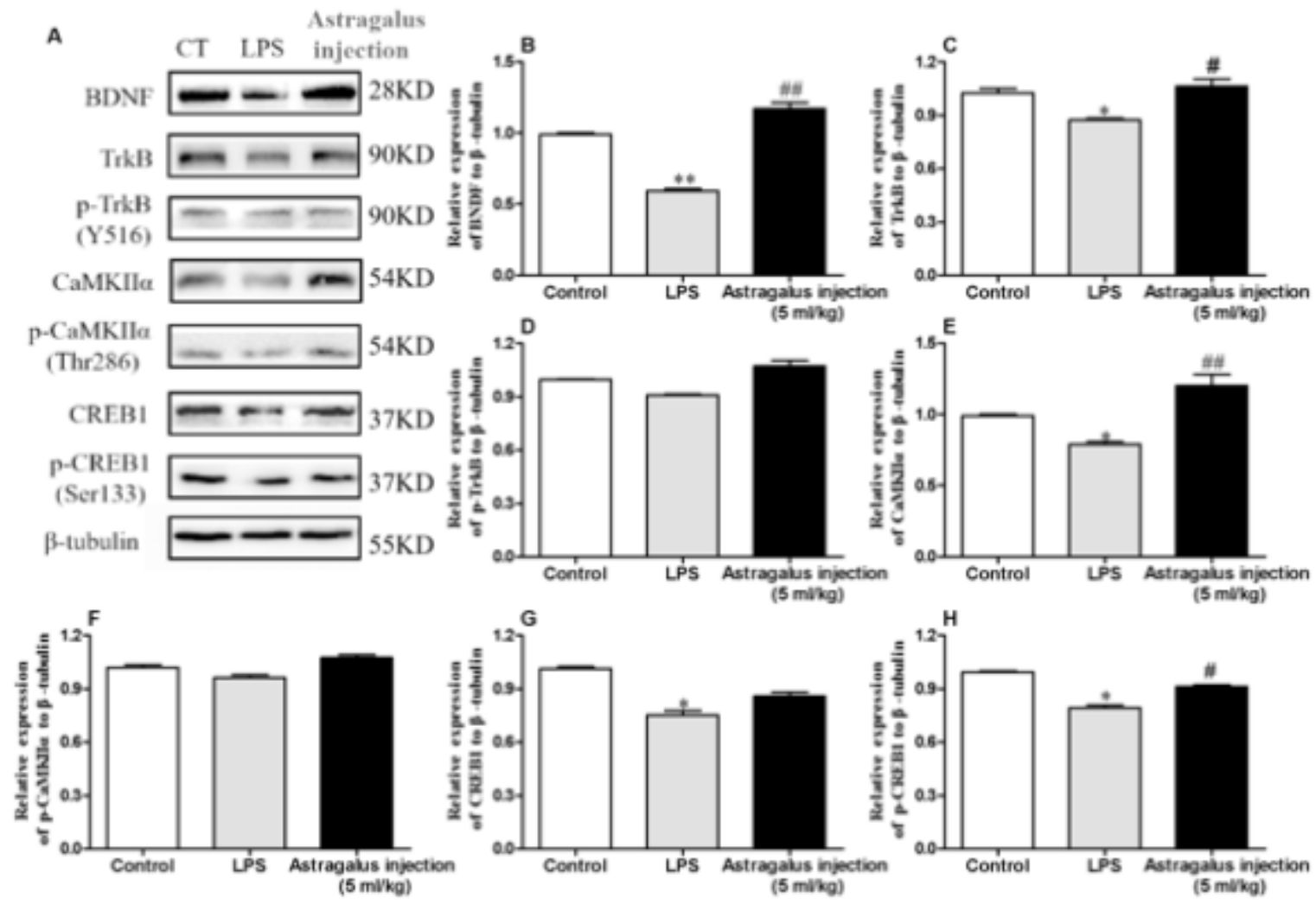

\section{Figure 16}

Effect of Astragalus injection on BDNF/TrkB/CaMKIla/CREB pathway in hippocampus. (A) Western blotting bands for hippocampal BDNF, TrkB, p-TrkB(Y516), CaMKIla, p-CaMKIla (Thr286), CREB1 and pCREB1 (Ser133); (B-H) Quantifification of hippocampal BDNF, TrkB, p-TrkB(Y516), CaMKIla, p-CaMKIla (Thr286), CREB1 and p-CREB1 (Ser133) western blotting analyses in A. Values are presented as means \pm $S D(n=6) .{ }^{*} p<0.05$ vs. the control group; $\# p<0.05$, \#\#p<0.01, vs. the LPS group. CT, Control. LPS, Lipopolysaccharide. 